\title{
Facile Synthesis of Biologically derived Fluorescent Carbon Nanoparticles (FCNPs) from an Abundant Marine Alga and its Biological Activities
}

\author{
MARIA THERESA F. CALANGIAN', ABIGAIL B. ILDEFONZO'1, VANESSA KATE S. \\ MANZANO', GENESIS JULYUST. AGCAOILI', REY JOSEPH J. GANADO², \\ ALLAN CHRISTOPHER C.YAGO ${ }^{3}$, EDUARDO R. MAGDALUYO, JR. ${ }^{4}$, \\ ROSS D.VASQUEZ ${ }^{5}$ and FRANCISCO C. FRANCO, JR. ${ }^{2^{*}}$
}

'Las Pinas City National Science High School, Carnival Park St., BFRV, Talon II, Las Pinas City, Philippines.

${ }^{2}$ Chemistry Department, De La Salle University, 2401 Taft Avenue, 0922 Manila, Philippines. ${ }^{3}$ Institute of Chemistry, College of Science, University of the Philippines, Diliman,

Quezon City, 1101 Philippines.

${ }^{4}$ The Department of Mining, Metallurgical, and Materials Engineering, College of Engineering,

University of the Philippines, Diliman, Quezon City, 1101 Philippines.

${ }^{5}$ Department of Pharmacy, Faculty of Pharmacy, University of Santo Tomas, 1015 Manila, Philippines.

${ }^{*}$ Corresponding author E-mail: francisco.franco@ dlsu.edu.ph

http://dx.doi.org/10.13005/ojc/340224

(Received: January 20, 2018; Accepted: March 25, 2018)

\begin{abstract}
Biologically derived carbon-based nanomaterials have been gaining attention in the recent years due to its various potential medical applications. In this study, fluorescent carbon nanoparticles (FCNPs) derived from an abundant alga, Cladophora vagabunda, is first reported. FCNPs with an average diameter of $\sim 43 \mathrm{~nm}$ was synthesized via hydrothermal process, a simple and green method. The synthesized FCNPs exhibited absorbances in the ultraviolet to visible regions and emissions at 600 and $650 \mathrm{~nm}$. Phytochemical screening and bioactivity tests were conducted to determine various bioactive compounds present in the FCNP surface and its antibacterial, antioxidant, and cytotoxic properties. Results showed that FCNPs from C. vagabunda contains tannin, saponin, flavonoids, and phenolic compounds which are known for their antimicrobial property as supported by the result of agar well diffusion method using a Gram-positive S. aureus and Gram-negative E. coli. Moreover, FCNPs shows inactive cytotoxicity using brine shrimp lethality test at ratio as high as $1: 1$ in $40 \%(\mathrm{v} / \mathrm{v})$ ethanol. The results suggest the potential use of FCNPs from C. vagabunda as a fluorescent material with various biological activities.
\end{abstract}

Keywords: Marine algae, Facile synthesis, Carbon nanoparticles, Optical properties, Biological activities.

This is an 2 Open Access article licensed under a Creative Commons Attribution-NonCommercial-ShareAlike 4.0 International License (https://creativecommons.org/licenses/by-nc-sa/4.0/ ), which permits unrestricted NonCommercial use, distribution and reproduction in any medium, provided the original work is properly cited. 


\section{INTRODUCTION}

For the last few decades, the development and application of nanomaterials continue to progress due to their excellent properties and tremendous potential applications in various research areas such as electronics, chemistry and biomedical sciences ${ }^{1-2}$. For biomedical applications, quantum dots (QDs) turned out to be successful for various applications, such as biological imaging and labeling, biosensing, drug delivery and cancer diagnostics, due to their luminescent property, narrow emission, broad excitation, high quantum yield and excellent photostability under harsh environment ${ }^{3-4}$. These QDs are composed of a semiconductor core, such as CdSe and CdTe, enclosed in a shell, such as $\mathrm{ZnS}$, to enhance its electrical and optical properties as well as to reduce the core metal leaching ${ }^{5}$. However, the growing potential of QDs in biomedical applications has raised considerable concerns regarding their toxicological impact. Indeed, in a recent in vivo studies using a mice subjects suggest that CdSe:ZnS quantum dots have high toxicity in the male reproductive system, can decrease in lamina propria, triggers the destruction of interstitial tissue, deformation of seminiferous tubules, and reduction of spermatogonia, spermatocytes, and spermatids ${ }^{6-7}$. Therefore, the search of alternative CdSe:ZnS nanomaterial for biomedical purposes must be explored.

Carbon nanoparticles (CNPs) is a potential substitute for quantum dots. Unlike semiconductor QDs, which uses heavy metal elements, this nanoparticle is generally small oxygenous carbon nanoparticles, which imparts easy modification, excellent water solubility, better biocompatibility, low toxicity, high chemical stability and low environmental hazard ${ }^{8-11}$. For these reasons, CNPs were successfully used for bioimaging ${ }^{12}$, DNA biosensing ${ }^{13}$, drug delivery ${ }^{12}$, photocatalysis ${ }^{14}$ and fluorescence probing ${ }^{15}$. Fundamentally, CNPs can be produced from carbon-enriched materials using the top-down or bottom-up approach. Top-down approach involves the cutting of carbon sources, which includes the use of laser ablation, arc discharge, electrochemical exfoliation and oxidative acid treatment, whereas bottom-up approach uses microwave/ultrasonic-assisted and hydrothermal carbonization ${ }^{8}$.
Since its discovery in 2004 by Scriven's group ${ }^{16}$, various carbon-based materials, such as, cellulose ${ }^{17}$, lignin ${ }^{18}$, fungus ${ }^{19}$, animal meat ${ }^{20}$, citrate $^{21}$, and ascorbic $\mathrm{acid}^{22}$ have been reported as starting material for CNP synthesis. However, CNPs derived from green natural materials containing heteroatoms have shown promising carbon source to replace chemical reagents in obtaining low toxicity nanomaterial via bottom-up method ${ }^{16}$. For example, Zhen Ngu et.al. ${ }^{23}$ demonstrated that carbon nanoparticle with fluorescence property can be derived from waste rice husks using thermalassisted carbonization at $120{ }^{\circ} \mathrm{C}$ with the aid of sulfuric acid. The produced carbon nanoparticle exhibits blue luminescence which can be quenched by adding various metal ions. Moreover, Guo et.al., ${ }^{24}$ showed the potential of microalgae biomass as a source of FCNPs using the hydrothermal method. The product produced showed emission peak at $435 \mathrm{~nm}$ using $360 \mathrm{~nm}$ excitation wavelength and negligible toxicity at concentrations as high as $400 \mu \mathrm{g} \mathrm{mL}^{-1}$. In addition, microalgae are considered as a sustainable source of carbon-based materials because of their high photosynthetic efficiency and faster growth rate even at wastewater ${ }^{25}$. Also, unlike the conventional biomasses, microalgae can be cultivated on marginal lands and cloned to double their weight within $24 \mathrm{~h}$ because they are single-celled organisms ${ }^{26-27}$. Therefore, microalgae can be a potential candidate for a sustainable source of FNCPs using a facile and low-cost method.

In the present study, we demonstrated for the first time the possibility of using an abundant alga, Cladophora vagabunda, as a raw material for synthesizing fluorescent carbon nanoparticles (FCNPs) using hydrothermal carbonization. The FCNPs were characterized with respect to its particle size, functional groups, and optical properties. This study also aims to identify the phytochemical compounds present in the surface of FCNPs, determine its cytotoxic activities, and its antibacterial activity against Staphylococcus aureus and Escherichia coli for possible medical applications.

\section{MATERIALS AND METHODS}

\section{Synthesis of Fluorescent Carbon Nanoparticles (FCNPs)}

Fresh Cladophora vagabunda samples were randomly collected from three sites [Figs. S1 
and S2 of Supplementary Information]: shore of Bubuin Island, shore of Napayung Island, and coastline of San Sebastian Island, Batangas, the Philippines using a mesh net. Samples were identified and authenticated by the Botany Division of the National Museum of the Philippines. Cladophora vagabunda were thoroughly washed, shade-dried for five hours, and pulverized using a blender. Finally, samples were sieved through a $212 \mu \mathrm{m}$ mesh to achieve uniform particles.

The synthesis of FCNPs was patterned based on the work of Paikaray et.al., ${ }^{28}$ with few modifications. First, $0.5 \mathrm{~g}$ of fine $C$. vagabunda powder was mixed with $150 \mathrm{~mL}$ of $40 \%(\mathrm{v} / \mathrm{v})$ ethanol solution in an Erlenmeyer flask. The solution was then poured into a $300 \mathrm{~mL}$ flask, covered with aluminum foil and heated at $200{ }^{\circ} \mathrm{C}$ in a furnace for one hour. After cooling down to room temperature, the as-prepared FCNP solution was centrifuged at
$6000 \mathrm{rpm}$ for $20 \mathrm{~min}$. and the supernatant was collected.

\section{Characterization of FCNPs}

The ultraviolet-visible (UV-Vis) spectrum of as-prepared FCNP solution was determined using HITACHI U-2900 Spectrophotometer. Functional groups present in the as-prepared FCNP solution was identified using Nicolet 6700 FT-IR Spectrometer. Fluorescence spectra of FCNP solution were gathered using PerkinElmer LS45 Fluorescence Spectrometer. Lastly, the particle size distribution was determined using Malvern-Zetasizer DLS.

\section{Phytochemical Screening}

Phytochemical screening analyses were carried out to determine the presence of various bioactive compounds in the FCNPs using standard methods as shown in Table 1.

\section{Table 1: Phytochemical screening analyses carried out in this study}

\begin{tabular}{lcc}
\hline Phytochemical present & Screening analysis & Literature \\
\hline cardiac glycoside & Killer-Kallani test & {$[29]$} \\
anthraquinone & Anthraquinone test & {$[30]$} \\
terpenoid and steroid & Copper acetate and Salkowski test & {$[30]$} \\
tannin & Ferric chloride test & {$[31]$} \\
saponin & Foam test & {$[32]$} \\
flavonoid & Alkaline reagent test & {$[33]$} \\
phenol & Lead acetate test & {$[30]$} \\
reducing sugar & Fehling's test & {$[34]$} \\
\hline
\end{tabular}

\section{Antibacterial Assay}

The agar well-diffusion method was used to assess the antibacterial activities of the asprepared FCNPs ${ }^{35}$. The antibacterial activity of the produced FCNPs was tested against Gram-positive Staphylococcus aureus (ATCC25923) and Gramnegative Escherichia coli (ATCC25922). Adjustments on the turbidity were first conducted by optimizing bacterial cultures to $0.5 \mathrm{McF}$ arland standards. Then, $100 \mu \mathrm{L}$ of the standardized cell culture was smeared onto four Mueller-Hinton agar plates. Four petri dishes of Gram-negative Escherichia coli were tested against FCNPs with four varying concentrations (as-prepared FCNP solution in $40 \%$ ethanol): $1: 1,1: 2,1: 4$, and 1:8. The same procedure was used for four petri dishes with
Gram-positive Staphylococcus aureus cultures. Each plate bore three wells that were filled with $20 \mu \mathrm{L}$ of the FCNP-ethanol solutions. The negative control was set to $40 \%(\mathrm{v} / \mathrm{v})$ ethanol while positive control was set to ampicillin. The plates were incubated for 24 hours. Then, the zone of inhibition was measured for each plate and recorded.

\section{Brine Shrimp Lethality Assay}

Cytotoxic activities of the FCNPs were evaluated by using the Brine Shrimp Lethality Assay $(B S L A)^{36}$. Artemia salina cysts were placed in a beaker containing $4 \%$ saline solution and placed under a lamp for $24 \mathrm{~h}$ allowing the cysts to hatch. After hatching, active nauplii were collected for the assay. In a 96-well microtiter plate, ten (10) nauplii 
were placed on each well with the addition of the as-prepared FCNPs of varying concentrations (1:1, $1: 2,1: 4,1: 8$ and $1: 16$ in $40 \%(v / v)$ ethanol). A controlled setup and a negative control of $40 \%$ ethanol were also included in the assay. All setups were left for two hours with a light source at room temperature. The number of nauplii that survived was then counted and \% mortality was calculated.

\section{RESULTS AND DISCUSSION}

\section{Synthesis and characterization of carbon nanoparticles (FCNPs)}

Figure 1 illustrates the procedure employed for the synthesis and characterization of FCNPs. Cladophora vagabunda is known to contain sterols, terpenoids, unsaturated fatty acids and lipids, such as glycolipids, triacylglycerols, phoquinovosyl diacylglycerol, galactolipids, phospholipids, etc. ${ }^{37-38}$ which can be a potential source of $\mathrm{P}, \mathrm{S}, \mathrm{O}$ and $\mathrm{C}$. FCNPs produced from Cladophora vagabunda is pale green in color under normal lighting conditions and emits red luminescence under UV light as shown in the left inset of Figure 2.

To confirm the functional groups present in synthesized FCNPs, the IR spectrum was collected as shown in Fig. 3(A). The characteristic absorption peak at $3427 \mathrm{~cm}^{-1}$ can be assigned to $\mathrm{O}-\mathrm{H}$ stretching vibrations $\mathrm{s}^{10}$. Moreover, the peaks at $2924 \mathrm{~cm}^{-1}, 1403 \mathrm{~cm}^{-1}$, and $653 \mathrm{~cm}^{-1}$ can be associated to stretching vibrations of $\mathrm{C}-\mathrm{H}, \mathrm{C}=\mathrm{C}$, and $\mathrm{C}=\mathrm{C}-\mathrm{H}$ out of plane bending, respectively ${ }^{37}$. The peak at $1700 \mathrm{~cm}^{-1}$ indicates the presence of symmetric/asymmetric stretching vibrations of $\mathrm{C}=\mathrm{O}^{10}$. Also, the bands at $1208-1370 \mathrm{~cm}^{-1}$ correspond to the $\mathrm{C}-\mathrm{N}$ group while the stretching vibration bands of $\mathrm{C}-\mathrm{O}$ and $\mathrm{P}-\mathrm{O}$ at approximately $1038-1170 \mathrm{~cm}^{-1}$ are due to the presence of carboxyl and other oxygen-containing functional groups ${ }^{16}$.

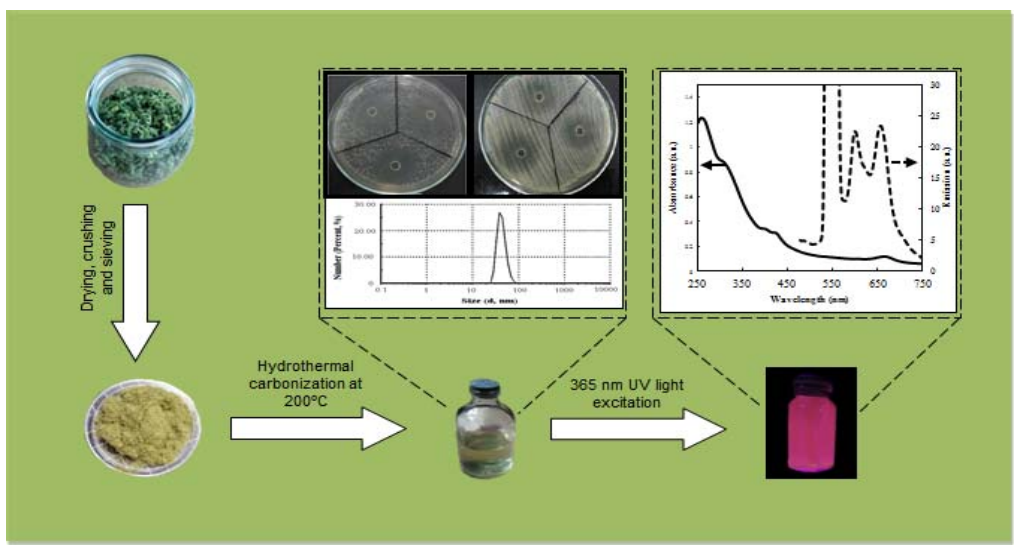

Fig. 1. (Color online) Overview of synthesis and characterization of FCNPs produced from $C$. vagabunda

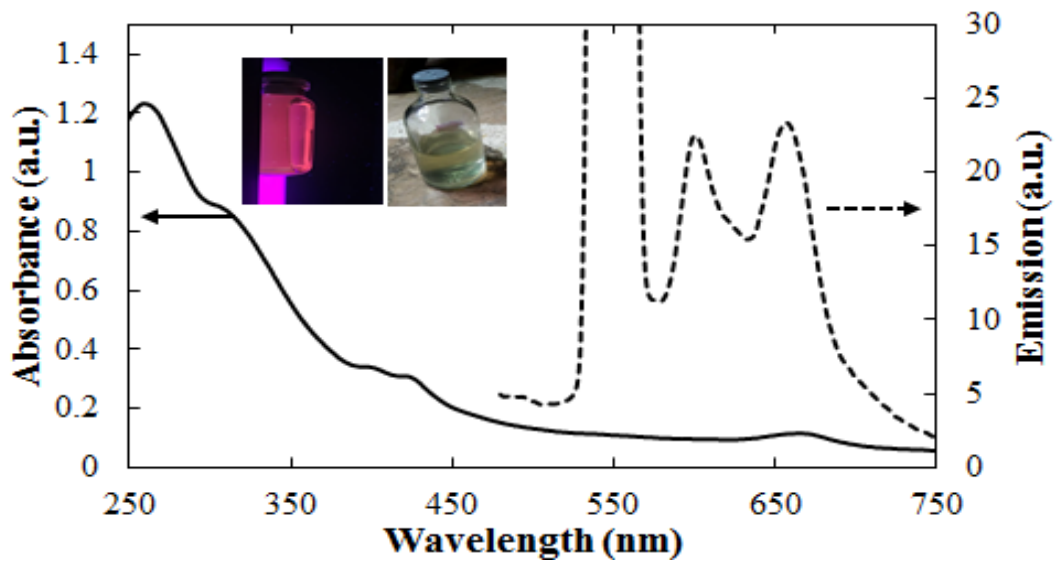

Fig. 2. (Color online) UV-Vis (solid line) and fluorescence (dashed line) spectra of as-prepared FCNP solution 
Dynamic light scattering (DLS) was employed to determine the particle size of synthesized FCNPs. As shown in Fig. 3(B), the asprepared FCNP solution contains nanoparticles with an average diameter of $42.78 \mathrm{~nm}$. This confirms that carbon nanoparticles (CNPs) were successfully synthesized from Cladophora vagabunda using the hydrothermal method.

\section{Optical properties of as-prepared FCNPs}

Optical properties, such as fluorescence, are important parameters for nanomaterials to be used for bio-imaging applications. The UV absorption, fluorescence excitation and emission spectra of the FCNPs are shown in Fig. 2. The absorption spectrum exhibits a peak at 260nm and a shoulder band at around $305 \mathrm{~nm}$, which can be ascribed to the typical absorption of an aromatic $\pi$ system or the $n-\pi^{\star}$ transition of a carbonyl group ${ }^{16}$ ${ }^{37-38}$. This observation is consistent with the IR results. Moreover, FCNPs produced from Cladophora vagabunda has two distinct emission spectra at around $600 \mathrm{~nm}$ and $650 \mathrm{~nm}$ when excitation energy of $550 \mathrm{~nm}$ was used which could be due to the presence of two chromophores with different energy levels. According to Das et al., ${ }^{54}$, single carbon dots could possess multiple chromophoric units associated with the carbon nanodot core. The same observation was reported by Ju et al., ${ }^{55}$ where they have demonstrated that full-color carbon dots have different color under the same excitation wavelength resulting to a broad emission band from blue to red region.
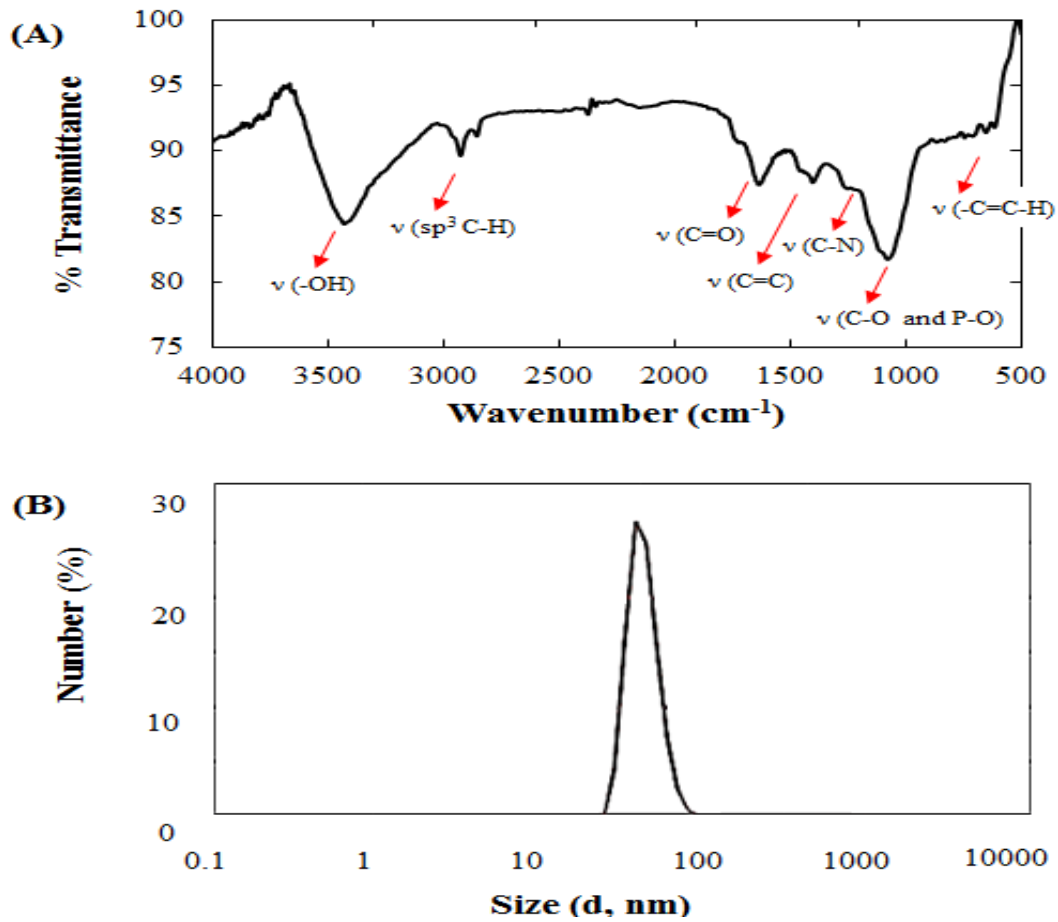

Fig. 3. (Color online) FTIR (A) and DLS (B) spectra of as-prepared FCNP solution

\section{Phytochemistry of as-prepared FCNPs}

Several studies emphasized that algal species are rich sources of phytochemicals, such as flavonoids, saponins, tannins, alkaloids, etc. which have been a particular interest in food and pharmaceutical field because of their potential to reduce the incidences of coronary heart disease, diabetes, cancers, and other chronic diseases ${ }^{39-40}$. Moreover, the biological nature of $C$. vagabunda poses lesser chances of side effects on human health rather than synthetically-based products.

FCNPs produced from $C$. vagabunda were screened for the presence of phytochemicals as shown in Table 1. A positive result for ferric chloride test suggests the presence of tannins. Tannins are natural polyphenolic compounds and plant secondary metabolites that are associated with 
plant defense mechanism ${ }^{41}$. For this reason, tannins are known to have biological activities, such as antimicrobial, anti-parasitic, antioxidant, anti-viral and anti-inflammatory properties ${ }^{42}$. FCNP from $C$. vagabunda is also positive for foam test which indicates the presence of saponin. Saponins are plant-derived biosurfactant ${ }^{43}$ and a biologically active glycoside consisting of a sugar moiety linked to a hydrophobic aglycone with a triterpenoid or a steroid structure ${ }^{44}$. Moreover, saponins have plasma cholesterol lowering effect in humans, which is important in reducing the risk of many chronic diseases and shows a strong cytotoxic effect against cancer cell lines ${ }^{45}$. Also, FCNPs from $C$. vagabunda showed positive results for flavonoids and phenolics which are known to have anticancer, antiinflammatory, antioxidant and antimicrobial properties as well|46-48.

Table 2: The number of Artemia salina that survived in control, negative control and increasing concentrations of FCNPs

\begin{tabular}{|c|c|c|c|c|c|c|c|c|c|c|}
\hline \multirow[b]{2}{*}{ Replicate } & & \multicolumn{3}{|c|}{ Trial 1} & \multicolumn{3}{|c|}{ Trial 2} & \multicolumn{3}{|c|}{ Trial 3} \\
\hline & & 1 & 2 & 3 & 1 & 2 & 3 & 1 & 2 & 3 \\
\hline A. & Controlled set-up & 10 & 10 & 10 & 10 & 10 & 10 & 10 & 10 & 10 \\
\hline B. & Negative control $(40 \% \mathrm{EtOH})$ & 8 & 9 & 8 & 8 & 8 & 9 & 9 & 8 & 9 \\
\hline C. & $1: 16$ as prepare FCNP solution in saline solution & 10 & 10 & 10 & 10 & 10 & 10 & 10 & 10 & 10 \\
\hline D. & $1: 8$ as prepare FCNP solution in saline solution & 10 & 10 & 10 & 10 & 10 & 10 & 10 & 10 & 10 \\
\hline E. & 1:4 as prepare FCNP solution in saline solution & 10 & 10 & 10 & 10 & 10 & 10 & 10 & 10 & 10 \\
\hline F. & $1: 2$ as prepare FCNP solution in saline solution & 10 & 10 & 10 & 10 & 10 & 10 & 10 & 10 & 10 \\
\hline G. & $1: 1$ as prepare CNP solution in saline solution & 10 & 10 & 10 & 10 & 10 & 10 & 10 & 10 & 10 \\
\hline
\end{tabular}

3.4 Bioactivity of as-prepared CNPs

Antibacterial assay against $S$. aureus and E. coli, and cytotoxic activity using brine shrimp lethality test were conducted to determine the biological activity of synthesized FCNPs from $C$. vagabunda.

A range of laboratory techniques has been developed in order to make assessments in terms of in vivo antimicrobial activities. One specific method is the so-called agar well diffusion routine which is the official method used in assessing the antimicrobial properties of plants extracts in many clinical laboratories ${ }^{49}$. As shown in Fig. 4, the zone of inhibition for both Gram-positive $S$. aureus and Gram-negative E. coli is dependent on the concentration of FCNPs. This suggests that FCNPs from $C$. vagabunda has antimicrobial activity against both Gram-positive and Gram-negative bacteria. This result is consistent with the study of Ristic et al., ${ }^{56}$, where GQD nanoparticle showed a concentration-dependent cytotoxic effect against $S$. aureus and $E$. coli when treated under UV light. However, in this study, the bioactivity of produced
FCNPs were active despite the absence of UV light. Also, the zone of inhibition is higher for $S$. aureus compared to $E$. coli at the same concentrations of FCNPs which shows its higher efficacy against the Gram-positive bacteria. The antibacterial property of FCNPs can be attributed to the presence of phytochemicals as previously discussed.

The brine shrimp lethality test was conducted to predict the preliminary toxicity which could provide a possible indication of cytotoxic properties of produced FCNPs ${ }^{52-53}$. Three replicates with three trials each were conducted, which is composed of controlled set-up, negative control $(40 \% \mathrm{EtOH})$ and increasing concentrations of FCNPs in saline solution as shown in Table 2. Surprisingly, no brine shrimp died for concentrations ranging from 1:1- 1:16 ratio of FCNPs in $40 \%(\mathrm{v} / \mathrm{v})$ ethanol, while the negative control shows an average of $15.6 \%$ mortality. This suggests that the as-prepared FCNPs from $C$. vagabunda exhibit inactive cytotoxicity and can be potentially used for bio-imaging and drug delivery. 

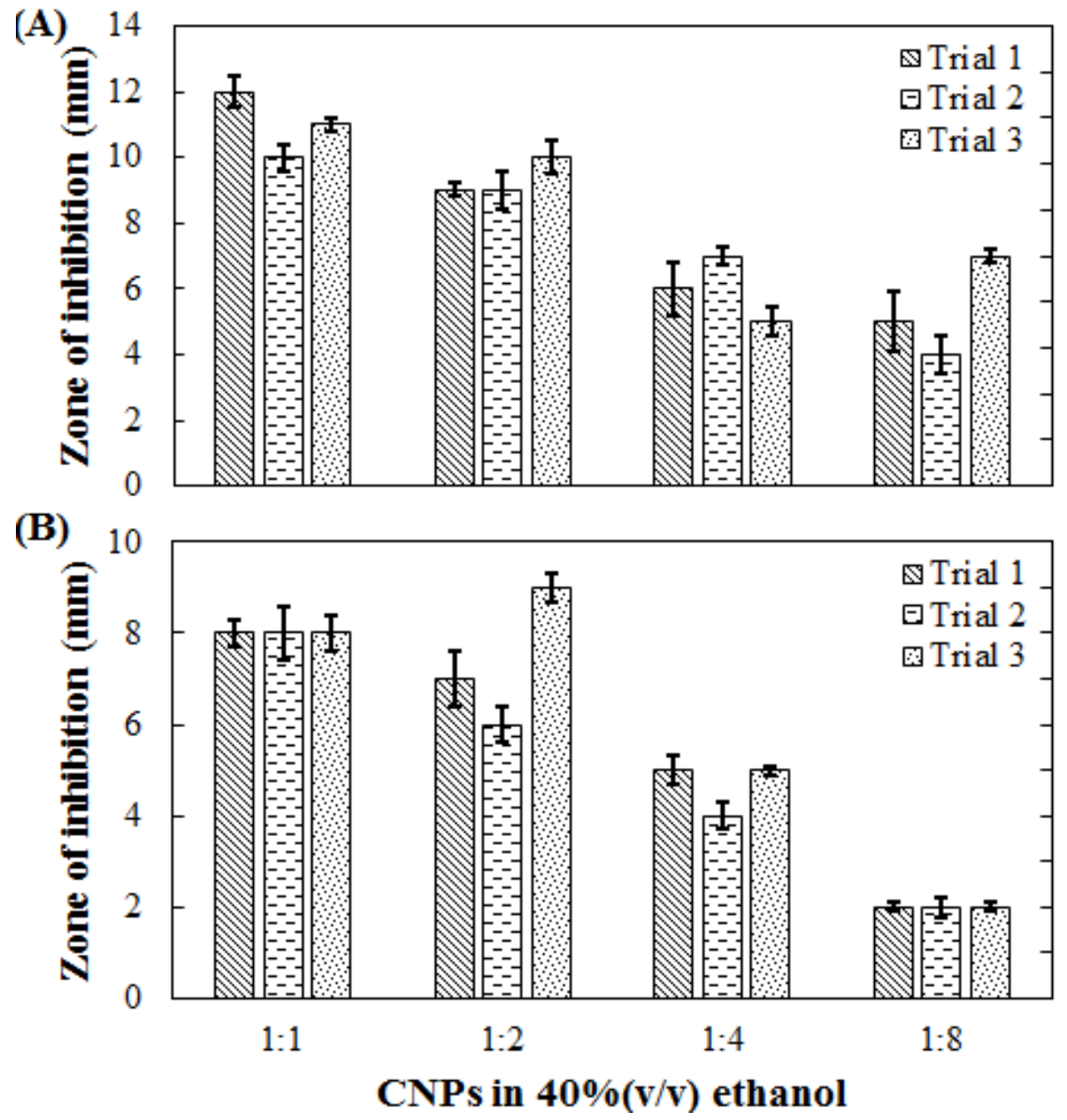

Fig. 4. Antibacterial activity of FCNPs against (A) S. aureus (B) and E.coli at different concentrations

\section{CONCLUSIONS}

We have demonstrated for the first time the synthesis of fluorescent carbon nanoparticles (FCNPs) from an abundant alga Cladophora vagabunda, using a green and facile method via the single-step hydrothermal process. The produced FCNPs absorbs light in the visible to UV regions and show emissions at $600 \mathrm{~nm}$ and 650 $\mathrm{nm}$ wavelengths. Moreover, phytochemical screening demonstrates the presence of tannin, saponin, flavonoid, and phenolic compounds which suggests its potential for future medical use. Furthermore, FCNPs produced from Cladophora vagabunda show antibacterial activity against Gram-positive S. aureus and Gram-negative E. coli, and inactive cytotoxicity based on brine shrimp lethality test. These results suggest that FCNPs derived from $C$. vagabunda has the potential to be used as a fluorescent material with various biological activities.

\section{ACKNOWLEDGEMENT}

We would like to thank Elijah Alves, and Kathlia de Castro-Crus for the assistance in the synthesis of FCNPs. We also acknowledge Ramoncito Luis de Boda, Catheleen Anne Ysulat, and Mia Angela Judicpa for the aid in DLS measurements. We are grateful to Esperanza Cabrera for providing bacterial cultures. The support of PCIEERD-DOST is also highly appreciated. 


\section{REFERENCES}

1. Zhang, Y.; Jiao, Y.; Liao, M.; Wang, B.; Peng, H. Carbon., 2017, 124, 79-88.

2. Fang, R.H.; Jiang, Y.; Fang, J.C.; Zhang, L. Biomaterials., 2017, 128, 69-83.

3. Jie, G.; Li, L.; Chen, C.; Xuan, J.; Zhu, J.J. Biosens Bioelectron., 2009, 11, 3352-3358 .

4. Hu, L.; Zeng, G.; Chen, G.; Huang, Z.; Wan, J.; Chen A. Colloids Surfaces B Biointerfaces., 2017, 159, 303-311.

5. Rosenthal, S.; Mcbrid, J.; Pennycook, S.; Feldman, L. Surf Sci Rep., 2007, 62(4), 111-157.

6. Amiri, G.; Valipoor, A.; Parivar, K.; Modaresi, M.; Noori, A.; Gharamaleki, H.; Taheri, J.; Kazemi, A. Int J Fertil Steril., 2016, 9(4), 512-520.

7. Valipoor, A.; Amiri, G.; Parivar, K.; Modaresi, M.; Taheri, J.; Kazemi, A.; Abasi, M.; Mirzakhani, A. Nanomed Journal., 2015, 2(4), 261-268.

8. Kang, E.B.; Lee, J.E.; Mazrad, Z.A.I.; In, I.; Jeong, J.H.; Park, S.Y. Nanoscale., 2018.

9. Ye, S.L.; Huang, J.J.; Luo, L.; Fu, H.J.; Sun, Y.M.; Shen, Y.D.; Lei, H.T.; Xu, Z.L. Chinese J Anal Chem., 2017, 45(10), 1571-1581.

10. Wu, Y.; Han, S.; J Lumin., 2016, 179, 595-601.

11. Tuerhong, M.; Xu, Y.; Yin, X.B. Chinese J Anal Chem., 2017, 45(1), 139-150.

12. Peng, Z.; Han, X.; Li, S.; Al-Youbi, A.O.; Bashammakh A.S.; El-Shahawi M.S.; Mohammad, S.; Leblanc, R.M. Coord Chem Rev., 2017, 343, 256-277.

13. Takalkar, S.; Baryeh, K.; Liu, G. Biosens Bioelectron., 2017, 98, 147-154.

14. Li, H.; Kang, Z.; Liu, Y.; Lee, S.T., 2012, 22(46), 24230.

15. Guo, Y.; Zhang, L.; Zhang, S.; Yang, Y.; Chen, X.; Zhang, M. Biosens Bioelectron., 2015, 63, 61-71.

16. Yu, C.; Xuan, T.; Yan, D.; Lou, S.; Hou, X.; Chen, Y. Sensors Actuators B Chem., 2017, 253, 900-910.

17. Da Silva Souza, D.R.; Caminhas, L.D.; de Mesquita, J.P.; Pereira, F.V. Mater Chem Phys., 2018, 203, 148-155.

18. Rai, S.; Singh, B.K.; Bhartiya, P.; Singh, A.; Kumar, H.; Dutta, P.K. J Lumin., 2017, 190, 492-503

19. Yang, K.; Liu, M.; Wang, Y.; Wang, S.; Miao, H.; Yang, L. Sensors Actuators B Chem., 2017,
251, 503-508

20. Zhao, C.; Jiao, Y.; Hu, F.; Yang, Y. Spectrochim Acta Part A Mol Biomol Spectrosc., 2018, 190, 360-367

21. Guo, Y.; Wang, Z.; Shao, H.; Jiang, X. Carbon., 2013, 52, 583-589.

22. Zhang, B.; Liu, C.; Liu, Y. Eur J Inorg Chem., 2010, 26(28), 4411-4414.

23. Ngu, P.Z.Z.; Chia, S.P.P.; Fong, J.F.Y.; Ng, S.M. New Carbon Mater 2016, 31(2), 135-143.

24. Guo, L.P.; Zhang, Y.; Li, W.C. J Colloid Interface Sci., 2017, 493, 257-264

25. Ripoll, N.; Silvestre, C.; Paredes, E.; Toledo, M. Int J Hydrogen Energy., 2017, 42(8), 5513-5522.

26. Jez, S.; Spinelli, D.; Fierro, A.; Dibenedetto A.; Aresta M.; Busi E. Bioresour Technol ., 2017, 239, 266-275.

27. Amarasekara, A.; Tanzim, F.S.; Asmatulu, E. Fuel., 2017, 208, 612-617.

28. Paikaray, S.; Moharana, P. 2013. A Simple Hydrothermal Synthesis of Luminescent Carbon Quantum Dots from Different Molecular Precursors. MSc thesis. Available from:http:// ethesis.nitrkl.ac.in/4627/1/411CY2027.pdf (2013), Accessed Dec. 1, 2017.

29. Khan, A.; Qureshi, R.; Ullah, F.; Gilani, S.; Nosheen, A.; Sahreen, S.; Laghari, M.; Laghari, M.; Rehman, S.; Hussain, I.; Murad, W. Journal of medicinal plants research 2011 , 5(25), 6017-6023.

30. Kardong, D.; Upadhyaya, S.; Saikia, L.R. J Pharm Res., 2013, 6(1), 179-182

31. María, R.; Shirley, M.; Xavier, C.; Jaime, S.; David, V.; Rosa, S.; Jodie, D. J King Saud Univ - Sci., 2017.

32. Trease, G.; Evans, W. Pharmacognosy, 11th ed. Bailliere Tindall, London, 1989, 45-50.

33. Saha, M.; Bandyopadhyay, P.K. Aquaculture., 2017, 473, 181-190.

34. Ismail, A.M.; Mohamed, E.A.; Marghany, M.R.; Abdel-Motaal, F.F.; Abdel-Farid, I.B.; El-Sayed, M.A. J Saudi Soc Agric Sci., 2016, 15(2), 112-117.

35. Jana, J.; Gauri, S.S.; Ganguly, M.; Dey, S.; Pal, T. Dalt Trans., 2015, 44(47), 20692-20707.

36. Kumar, P.; Selvi, S.; Praba, S.; Selvaraj, A.; Rani, L.; Suganthi, P.; Govindaraju, M. Digest Journal of Nanomaterials and Biostructures., 
2012, 7(4), 1447-1455.

37. Liang, Q.; Ma, W.; Shi, Y.; Li, Z.; Yang, X. Carbon., 2013, 60, 421-428.

38. Beiraghi, A.; Najibi-Gehraz, S.A. Sensors Actuators B Chem., 2017, 253, 342-351.

39. Whankatte, V.; Ambhore, J., International journal of science and nature, 2016, 7(3), 659-663.

40. Li, Z.; Jiang, H.; Xu, C.; Gu, L. Food Hydrocoll., 2015, 43, 153-164.

41. Gun'ko, V.M.; Lupascu, T.; Krupska, T.V.; Golovan, A.P.; Pakhlov, E.M.; Turov, V.V. Colloids Surfaces A Physicochem Eng Asp., 2017, 531, 9-17.

42. Huang, Q.; Liu, X.; Zhao, G.; Hu, T.; Wang, Y. Potential and challenges of tannins as an alternative to in-feed antibiotics for farm animal production. Anim Nutr., 2017.

43. Kurniawati, H.A.; Ismadji, S.; Liu, J.C. Bioresour Technol., 2014, 166, 429-434.

44. Hostettmann, K.; Marston, A. Chemistry and pharmacology of natural products. In: Phillipson, J.D., Baxter, H. (Eds.), Saponins. Cambridge University Press, UK., 1995.

45. Mudryj, A.; Yu, N.; Aukema, H. Appl. Physiol. Nutr. Metab., 2014, 39 (11), 1197-1204.

46. Sharma, O.P.; Bhat, T.K. Food Chem., 2009,
113(4), 1202-1205.

47. Balouiri, M.; Sadiki, M.; Ibnsouda, S.K. J Pharm Anal., 2016, 6(2), 71-79.

48. Liu, J.; Pu, H.; Liu, S.; Kan, J.; Jin C. Carbohydr Polym., 2017, 174, 999-1017.

49. Spagnuolo, C.; Moccia, S.; Russo, G.L. Eur J Med Chem., 2017.

50. Raffa, D.; Maggio, B.; Raimondi, M.V.; Plescia, F.; Daidone, G. Eur J Med Chem., 2017, 142, 213-228.

51. Brand-Williams, W.; Cuvelier, M.E.; Berset, C. LWT - Food Sci Technol 1995, 28(1), 25-30.

52. Primahana, G.; Ernawati, T.; Dewi, N.L.P.; Dwiyatmi, I.D.; Darmawan, A.; Hanafi, M. Procedia Chem., 2015, 16, 694-699.

53. Tanamatayarat, P..Engl. Asian Pac J Trop Biomed., 2016, 6(12), 1050-1055.

54. Das, S.K.; Liu, Y.; Yeom, S.; Kim, D.Y.; Richards, C.I. Nano Lett., 2014, 14(2), 620-625.

55. Ju, B.; Nie, H.; Liu, Z.; Xu, H.; Li, M.; Wu, C.; Wang, H.; Zhang, S.X.A. Nanoscale 2017, 9(35), 13326-13333.

56. Ristic, B.Z.; Milenkovic, M.M.; Dakic, I.R.; Todorovic-Markovic, B.M.; Milosavljevic, M.S.; Budimir, M.D.; Paunovic, V.G.; Dramicanin, M.D.; Markovic, Z.M.; Trajkovic, V.S. Biomaterials., 2014, 35(15), 4428-4435. 